\title{
Perception of E-Learning by Consumers of Educational Services
}

\author{
Oksana Bogdanova ${ }^{1, *}$ \\ ${ }^{1}$ Southern Federal University, Bol'shaya Sadovaya st. 105/42., 344006 Rostov-on-Don, \\ Russia
}

\begin{abstract}
This paper attempts to assess the perception of online learning by consumers of educational services. The study is based on the cognitive approach, interpreting the person as a cognitive system, which is influenced by the communication arising in the learning environment, and education is defined as a process of communication, where the associated problems have a negative impact on the final educational product. We revealed the indicators which determine the perception of online education, among which we can name the following: the quality of communication, convenience of tools, students' motivation and their ability to selforganization, responsiveness to innovations. The analysis of the scientific literature revealed that the works devoted to the perception of online education are of a private nature, depending on the specific country and its situation at the market of educational services. This puts the Russian scientific community in front of the need for scientific understanding of the perception of online education based on the situation observed in Russian higher education. It is concluded that the main problem of the image of Russian online education is an attempt of the Ministry of Education to combine two mutually exclusive approaches: to use online education as an innovative way to train specialists and the possibility to reduce the cost of the classical education. According to the author, online-education is not a competitor to classical education, because it is focused on a different audience and is based on different methodological and didactic principles. That is the reason why the work on improvement of perception of elearning should begin with defining its place in the sphere of Russian education and the decision about it should be made by the Ministry of Education.
\end{abstract}

\section{Introduction}

The modern world dictates new requirements to the educational sphere. Today's highly qualified specialists need not only qualitative theoretical and practical knowledge, but also a set of competences, which will make them competitive on the constantly changing labor market. The 21 st century professions are directly connected with the development of ITtechnologies and are meant for digital natives. It means that the requirements to their

\footnotetext{
*Corresponding author: pk-iser@mail.ru
} 
training are also changing and should acquire adaptive, mobile, and global character. Professions such as social media manager, internet marketer, accountant, programmer, SEO optimizer, advertising specialist, designer and other most popular and "trendy" professions are changing rapidly, where trends, tools and approaches to work change every year or even faster. This makes us realize that classical university education does not meet the abovementioned requirements for adaptability and will be ineffective in training specialists in innovative professions. In this regard, online learning, which is adaptive, global and allows to implement the training of practice-oriented professionals in the shortest possible time, is of particular relevance. We believe that the modern world has divided the educational environment into the classical academic and practice-oriented ones. The former, as the name implies, gives priority to the student's initiation into higher education, instilling an interest in science and the pursuit of new knowledge. It teaches young people to "learn", based on time-tested scientific principles, while the practice-oriented environment, by contrast, aims to teach students to work in a field of interest to them in the shortest possible time. All the above-mentioned allows drawing a demarcation line, which divides "innovative" and "classical" education. It is worth mentioning that universities use innovative technologies, but this does not change the general classical approach of teaching scientific disciplines. It becomes obvious that innovative and classical education should be based on different methodological and didactic principles. Classical education makes a person an intellectual, while innovative education makes him a specialist.

Online-education is the most innovative solution in educational technology, and it is based on the strong points of the global net, wide availability of gadgets and high digital literacy of digital native students born in the 21 st century. It allows not only teaching young specialists online, but also reorienting the educational process and making it possible to organize it around students' self-organization. Online-learning is a hot research topic and a lot of scientists around the world focus their attention on the prospects and problems of its implementation. It is worth noting that in Western civilization and developed countries online learning has been institutionalized long ago and has an established character, but in the countries of Eastern Europe, Asia, developing countries in South America and North Africa, it is just starting to spread. This justifies the widespread in the scientific discourse of Chinese, Arab, Indian and Brazilian researchers. Russian scientific thought also paid attention to the issues of online learning and how it should be implemented in the education system.

Let us briefly review the scientific literature, demonstrating the direction of re online learning research. Lister made an attempt to assess the inclusiveness of online education and to identify how well it is suitable for working with students with health problems [10], Dranghici conducted experiments related to determining the patterns of behavior of students studying online [3], Lee established the relationship between the ability of students studying online to self-organize and their academic performance, where it is determined that the ability of a person to self-organize determines the success of knowledge transfer [9]. Wang studied the prospects of gamification of online learning and the use of interactive technology in the educational process, implemented online [15], and Han developed a methodology for determining the academic performance of students depending on their patterns of behavior in the classical and online learning [4]. As can be seen from the above, online learning is an object of scientific reflection and is quite popular among researchers who focus on its problems and prospects.

A particularly important area for research, in our opinion, is the analysis of the perception of online learning by consumers of educational services. It is worth noting that online learning is primarily a service, not a social good, hence the quality of this service will shape the final educational product. Ibrahim studied the degree of acceptance and trust to online learning as an effective way to train students of medical educational institutions 
[6], Bauk conducted an educational experiment, evaluated and compared students' perception of online learning and face-to-face learning [2], Alkhalaf revealed, that online learning has a positive effect on faculty performance [1], Kimiloglu sets a more specific goal and studies the perception of online learning in corporate education and training [7], Tao applies cluster analysis to typologize student and faculty behavior during online learning [14].

Russian scientific discourse lacks empirical information about the mechanisms of online learning and is mainly concentrated around the enumeration of its advantages and disadvantages. It is worth noting that there are no attempts of theoretical understanding of online learning and development of methodology related to its implementation, which suggests that Russian researchers do not have a deep understanding of the online learning market and its impact on the educational environment. The studies conducted by Kovalev and Lubsky are noteworthy as they are based on empirical information and allow to determine the attitude of Russian students towards online education [11]. They hold the position that "onlineization" of higher education is associated with the loss of quality of the educational product and does more harm than good in modern Russian realities [8]. The Russian scientific discourse about online education is fragmented, as most researchers conduct point studies aimed at analyzing a specific educational institution, but rarely make attempts to approach this issue more holistically and try to extrapolate the data on all online education in Russia. We believe that online learning is difficult to theorize because of its essence, which is that it emphasizes self-learning, self-organization and is generally aimed at emphasizing the individuality of the student, which complicates attempts to scientifically systematize the practices implemented in online learning.

Thus, online learning is an object of scientific interest, but its comprehension is complicated by its fragmentary nature associated with the difference of online learning practices in each individual country. This leads us to the understanding that the effectiveness of online learning is related not only to technical means, but also to the characteristics of the socio-cultural and educational environment in which it is implemented. In this study we will try to structure the main problem fields associated with the perception of online learning by consumers of educational services and form a set of recommendations to optimize online learning.

\section{Materials and methods}

The study is based on the cognitive approach, which treats the human being as a cognitive system experiencing communication that occurs in a learning environment [13]. Within the framework of this article education will be treated as a process of communication, which is inherent in all the features of this process, including noise, communicative failures, peripheral and central ways of assimilation of information.

The empirical base consists of the studies conducted by Russian and foreign scientists who focus their attention on the issues of on-line learning and its practical implementation. The main method of research is a critical analysis of the scientific literature on the problem of online learning. The perception of online learning by consumers of educational services is based on the quality of communication, convenience of tools, student motivation and sensitivity to innovation. Students' perception of Russian online learning will be assessed by the above-mentioned indicators, which will make it possible to conclude about the peculiarities of the perception of online learning by consumers of educational services.

\section{Results}


As mentioned above, education can be interpreted as a communication between an instructor and a student in which information is exchanged. This, in turn, means that students assimilate this information. Obviously, the process of information assimilation will vary from case to case, and it is almost impossible to generalize it. We will resort to the approach of Richard Petty and John Cacioppo, that researched the process of information assimilation [12]. To begin with, communication in the educational process has a persuasive character, where the teacher broadcasts this or that information to students in the hope of their successful understanding. This understanding is divided into two paths: central and peripheral. The first is related to the perception of information from the position of arguments, facts, and implies a rational comprehension of the message received. It can be considered a reference scenario of learning material assimilation. The second way is characterized by a superficial understanding of the subject, where the main connections of the student's consciousness with the taught material are superficial or peripheral in nature. Needless to say, that in the case of peripheral understanding of the material academic achievement will be low, and students' understanding of the material will be unsatisfactory. The communication between the teacher and the student can also be subject to communication noise, which is easier to identify in online learning. They are related to technical malfunctions that occur during the interaction between the instructor and the student. The most common can be connection interruptions, low speed Internet connection, poor quality webcams, microphones without noise isolation and other problems related to the technical implementation of online learning. Communicative failure in online learning is a pressing problem because the format itself implies a significant amount of difficulty in communicating the message. If the communication takes place in text format, mistakes and abbreviations can prevent full understanding of what is going on, and communication with the lecturer by means of voice communication can be easily interrupted by someone else. It is also influenced by the fact that often a lecturer works "in vain", where he reads prepared material but cannot see the feedback from students, which reduces his motivation to deliver material to the addressees. For this reason, we believe that lectures that do not involve interaction between students and teachers are not suitable for online learning and should be replaced by recorded audio/video materials, presentations, or notes.

Let us move on to the allocation of indicators of satisfaction of consumers of educational services with the implementation of online learning.

The quality of communication. It is determined by the absence of technical problems and established socio-cultural environment. The impact of technical failures on the quality of communication is very easy to explain because it determines whether the message will be delivered to the recipient, but the socio-cultural environment is more difficult to describe. To begin with, the scientific community has not defined what sociocultural environment can be considered favorable for online learning. In classical education this question is solved by the accessibility of the teacher and the possibility to consult with him, but online learning implies asynchronous communication with the teacher with the help of media mediators, which does not allow making any specific requirements. If the communication between teachers and students is predominantly text-based, it becomes difficult to determine how and when teachers should be available. If it is a verbal contact format, then the question of allocating specific "Opening hours" that are made for receiving questions becomes relevant, which, unfortunately, is not very different from classical teaching and does not suit online learning in its format. In this regard, we believe that the sociocultural environment of online education should consist not only of the teacher, but also include additional actors, such as consultants and curators. The teacher's time is limited, and students' questions online should require a timely response and that is why it is necessary to introduce additional participants of the educational process who have the necessary competences. Thus, the quality of communication is determined by the absence 
of technical failures and the presence of optimal sociocultural environment, characterized by readiness of the subjects of the educational process to communicate asynchronously, without experiencing serious difficulties in communication.

Convenience of tools. Online-education imposes higher requirements to the organization of the working space than the classical face-to-face education. To begin with, online learning is media mediated, students interact with each other and with the teacher through the keyboard, mouse, microphone, webcam, smartphone, tablet, and other means. This means that the primary means of interaction must meet the demands of the time. One of the benefits of online learning is the blurring of boundaries of educational spaces and increasing accessibility of higher education to a wider range of people. online education supporters regularly repeat two arguments: cheapness and accessibility. However, these arguments work only in theory, but not in practice. Firstly, the audience that the initiators of online learning want to involve in the educational process, often does not have the necessary technical equipment. Smartphones often do not meet the technical requirements, PCs are outdated, and laptops can lose battery charge during two classes. Thus, from the technical point of view, online education is in a very vulnerable position, unlike classical education, because the number of variables that determine the quality of communication is much higher. The other side of the question related to the convenience of the tools is the compliance of the online education platform with all the requirements that are set for it. These include:

1) the ability to solve tests without connecting third-party applications;

2) availability of interactive "blackboard", which allows you to represent simple and understandable figures;

3) broadcasting videos and pictures outside of the "share screen" function;

4) the ability to check and demonstrate homework assignments;

5) rooms for student groups in which text and audio/video communication can take place;

6) workspaces where students can collaboratively complete the same text document, edit photos (at a basic level), and play videos.

The list could grow endlessly, as students' demands for technical support are constantly growing, but educational institutions rarely can keep up with them. If we turn to the practical experience of online education in Russia, we can look at the example of Southern Federal University, which has chosen the Microsoft Teams platform for distance and online learning. The problem lies in the program itself since it is not designed for educational purposes and is positioned as a space for organizing business meetings and dialogues. Students cannot gather outside of scheduled "classes" that are created by instructors. The presence and absence of students is monitored by the administration of the university in order to report on the implementation of online technologies in the educational process. Needless to say, that the tools described above, which improve the quality of the educational process in online mode, are not present in this software. There is an opportunity to share the screen, video link and file sharing. It follows from all this that if a federal university, which has authority and reputation, uses software, which is not designed for educational purposes, it will inevitably lead not only to the decline of quality, but also to the decline of students' motivation. So, the availability of necessary tools and the ease of their use is a determining factor of effectiveness of online education. The tools described above are what distinguishes online learning from the "digitized" classical one.

Students' motivation and their ability to organize themselves. is the third indicator that determines the quality of online education. Since online learning implies the accentuation of individuality of each learner and prioritizes their needs, their motivation will be one of the most important factors influencing their experience in online learning. We believe that students' motivation will depend, first and foremost, on the correspondence of online learning to the format itself. If we again turn to the experience of Southern Federal 
University in the implementation of online learning, we can conclude that it does not differ from correspondence distance learning or from full-time classic education. This is explained by the fact that the distant nature of online learning is in fact realized in students receiving a task for a month or a whole semester, given all the necessary materials and they are put before the need to fulfill them to get credit. Communication with the instructor is spontaneous rather than structured. Students are forced to communicate with each other through social networks and messengers, their interaction with each other is only related to the joint performance of work, they do not socialize and do not fill themselves with the "context" of the discipline studied, they are not aware of the practical application and experience a decline in motivation to learn. It is transformed into imitational activity aimed at meeting the demands of the instructor rather than self-development. This obviously goes against the very concept of online learning and allows us to say that such work with students is a bad example of implementation of online learning. On the other hand, if students who study online are not "abandoned," they face the problem that they are actually studying in face-to-face format, but not in the classrooms of the university, but at home. Such an approach is completely inappropriate for online learning, as it mixes classical education and online meetings, which, in turn, is bad for contact interaction and does not increase students' motivation to work on their own development as professionals. Online learning implies the creation of an environment that encourages self-organization of student work and the desire for independent information retrieval, and contact with the teacher, supervisor and advisor is asynchronous and exists to help students work with challenging studies. Thus, we can conclude that the substitution of online education by distance or classical, driven into a digital format has a bad impact on students' motivation to learn. The right approach in this situation is to create a sociocultural environment that encourages student self-organization, gives priority to their individual needs, and motivates them to study on their own, aimed not at getting formal grades, but at acquiring the necessary and practically applicable competencies. Students' ability to self-organize derives from motivation, as it determines the student's desire to acquire new knowledge, to prioritize it and to allocate his/her time effectively.

Susceptibility to innovations. This indicator is the most complex and requires attention, as it relates to many subjects. Let us start with the receptivity to innovations at the macro level. It includes the state, society, educational services market, labor market, and students themselves and their affiliated stakeholders. The interest of the state in the promotion of online education is a key moment, which determines the vectors of its development. Many developing countries are striving to come to online education because of the poor quality of classroom education and its inaccessibility to large segments of the population. We can say that in this situation there are simply no alternatives and the organizers of the educational space simply "jump over" the classical full-time education and go straight to the online learning. The situation in the Russian Federation is different, because it has already had an established and time-tested system of classical education, and Russian higher school is a respected formation recognized all over the world. In the situation of classical education success, there is just no sense for the state to promote online education to achieve high results, because they are achievable with the existing system. The main reason for the implementation in the Russian social reality of online education is to reduce budget expenditures on public universities using online technologies in several courses and disciplines. We can say that the Ministry of Education is not so much interested in online education as a generator of real results, but to save money. This approach has a bad effect on the educational process, the motivation of students and teachers, and generally strikes a blow to the Russian educational system.

The image of online education in society is also shaped by the state's purely formal intentions. Since it is in the shadow of classical higher education, students' confidence in it 
is extremely low. Teachers who work in classical full-time education are skeptical about online learning. All the above creates a public consensus that online education is worse than classical education. Public opinion is projected onto students and their parents (who pay for their education), which leads to distrust of online learning as an effective way to educate higher-education professionals. Public aversion to online education has an impact on the labor market, where graduates trained online are not in demand, which, in turn, puts students in an apathetic state and has a negative impact on their desire to achieve any success in education [5]. All the above-mentioned allows us to conclude that online education is not perceived as an effective way of training specialists and is associated with a high degree of distrust of the significant actors of the educational space.

Thus, Russian online learning is associated with many difficulties connected with the mismatch of educational platforms to technical requirements, problems at the level of communication, the decline of student motivation and the interest of the Ministry of Education in online learning only as a means of saving budget funds. That leads us to the conclusion that the perception of online learning in Russia can be assessed as unsatisfactory and in need of serious optimization.

\section{Discussion}

Russian online education is experiencing problems with its perception by consumers of educational services, which leads us to the need to develop practical recommendations that will solve some of the problems and improve its reputation.

As we said earlier, education is communication. Problems with communication lead to poor learning, and this, in turn, leads to poor academic performance, which lowers students' motivation for self-improvement. Legislators and administrators of Russian universities should come to understand that online education is a different process than distance, correspondence, and full-time education, which requires a completely different approach to its organization. The low cost of online learning and the opportunity to attract a wide audience can become positive features only after the creation of an educational environment that allows for the implementation of online education properly. We see the most rational step here as giving up renting platforms for business meetings like Microsoft Teams and Zoom, which are the most popular in Russian higher education, and focusing on creating our own platform for online learning. This will also solve the problem of convenient and understandable tools, as this platform, by its idea, should be developed considering the needs of students and teachers. The transition of online learning to specialized software will have a positive impact on the perception of this type of learning and will open new opportunities for learning for many students.

The receptivity of consumers of educational services to innovation, that is, the willingness to accept online learning, should be increased by demonstrating the real results of online learning. This can be realized through the promotion of graduates who have studied online as in-demand specialists in the labor market. However, to bring this idea to life it is necessary to make the Ministry of Education and the Government understand that online education is not the way to save budget money, but an alternative, which allows making higher education available to a wide range of people. This does not mean savings, but a significant investment in the development of an online working infrastructure.

The main problem of perception of online education, in our opinion, is the erroneous understanding of all the actors of the educational space about the positioning of this type of education in the market of educational services. It should not be a substitute for a classical education, it has other aims, it is aimed at a certain audience and has little in common with classical higher education. Online-education does not educate intellectuals, does not form interest to science and does not socialize students into higher education. It is primarily 
aimed at teaching students the skills they need to do the work in which they are interested. Classical education, on the contrary, creates fundamentally different specialists and therefore the positioning of online education as a full-fledged alternative to the classical one is incorrect and misleading for potential students.

To improve the image of Russian online education it is necessary to position it as accelerated, practice-oriented courses aimed at forming the necessary competences in applied disciplines. We can say that sociologists, philosophers, educators, historians, physicists, and mathematicians remain in classical education, because they are related to science, while marketers, advertisers, managers, and programmers can easily be trained online, because their specialties are practical in nature, not requiring serious immersion in the "context" of the profession. In other words, classical education educates intellectuals, while online education creates specialists. If we draw a clear demarcation line between them and recognize the achievements of online learning in the information space, its perception will improve, and student motivation will increase. We also recommend removing online learning from of state universities and making it completely commercial. This will solve the problem of conflict of interest, observed in federal universities, where teachers are afraid of being fired because of the introduction of online education.

\section{Conclusions}

Summarizing all the above, we can conclude that the problems associated with the perception of online learning by consumers of educational services depend primarily on the inconsistent policy of the Ministry of Education, which promotes online education as an innovative way to train high-class specialists at the same time positioning it as an opportunity to save budget funds allocated to the educational sphere. Online-education at the stage of its birth and institutionalization cannot be cheap and effective at the same time. The uncertainty of the Ministry of Education with the identity of online learning leads to confusion among students. It manifests itself in the fact that they learn with the help of innovative technologies, but online learning is implemented on non-designated platforms, rented from Western corporations. Russian online education at state universities is in fact a digitized classical or correspondence education, which does not relate to the principles of organizing online education.

Asynchrony of communication of subjects of the educational process, respectful attitude to individual characteristics of every student, encouragement of self-organization and selflearning are the main principles which distinguish online education from other types. Substitution of online learning for classical or correspondence education leads to a decline in motivation and trust in the effectiveness of educational practices, which in turn reduces the reputation of online learning among the many actors interested in it. For this reason, solving the problems of perception of online learning depends on the decisions made by the Ministry of Education and university administrations. They need to clearly decide whether they want to see online learning as a full-fledged platform for training specialists or leave it as an appendage of classical education, allowing to save on less popular and important courses and disciplines.

The perception of online learning by consumers of educational services can be achieved only with the real results connected with the production of a competitive educational product. Considering that online learning in most cases is under the wing of state educational institutions, the first steps should be made at the level of bodies which control the educational environment.

\section{References}


1. S. Alkhalaf, S. Drew, R. AlGhamdi, O. Alfarraj, E-Learning System on Higher Education Institutions in KSA: Attitudes and Perceptions of Faculty Members. Procedia - Social and Behavioral Sciences, 47, 1199-1205 (2012) https://doi.org/10.1016/j.sbspro.2012.06.800

2. S.I. Bauk, Assessing student's perception of e-learning in blended environment: an experimental study. Procedia - social and behavioral sciences, 191, 323-329 (2015) Doi: 10.1016/j.sbspro.2015.04.393

3. A. Draghici, A. Popescu, G. Fistis, C. Borca, Behaviour Attributes that Nurture the Sense of E-learning Community Perception. Procedia Technology, 16, 745-754 (2014) https://doi.org/10.1016/j.protcy.2014.10.024

4. F. Han, R. Ellis, Predicting Students' Academic Performance by Their Online Learning Patterns in a Blended Course: To What Extent Is a Theory driven Approach and a Data driven Approach Consistent? Educational Technology \& Society, 24(1), 191-204 (2021) doi:10.2307/26977867

5. M. Hung, C. Chou, C. Chen, A. Own, Learner readiness for online learning: Scale development and student perceptions. Computers \& Education, 55(3), 1080-1090 (2010) https://doi.org/10.1016/j.compedu.2010.05.004.

6. N.K. Ibrahim, et all., Medical students' acceptance and perceptions of e-learning during the Covid-19 closure time in King Abdulaziz University, Jeddah. Journal of Infection and Public Health, 14(1), 17-23 (2021)

7. H. Kimiloglu, M. Ozturan, B. Kutlu, Perceptions about and attitude toward the usage of e-learning in corporate training. Computers in Human Behavior, 72, 339-449 (2017) https://doi.org/10.1016/j.chb.2017.02.062

8. V.V. Kovalev, A.V. Dyatlov, K.V. Vodenko, Evaluating the quality of online education (based on the materials of focused interviews in student groups). Bulletin of the South Russian state technical university. Series: Socio-economic sciences, 13(3), 614 (2020)

9. J. Lee, W. Lee, The relationship of e-Learner's self-regulatory efficacy and perception of e-Learning environmental quality. Computers in Human Behavior, 24(1), 32-47 (2008) https://doi.org/10.1016/j.chb.2006.12.001

10. K. Lister, V.K. Pearson, D. Collins, G.J. Davies, valuating inclusion in distance learning: a survey of university staff attitudes, practices and training needs, Innovation. The European Journal of Social Science Research (2020). Doi: 10.1080/13511610.2020.1828048

11. A.V. Lubsky, V.V. Kovalev, From online high school to online education. Humanitarian of the South of Russia, 9(2), 33-50 (2020)

12. R. Petty, J. Cacioppo, Communication and persuasion: central and peripheral routes to attitude change. Springer series in social psychology (1986) ISBN: 978-0387963440

13. S.V. Sergeev, Cognitive Pedagogy: Peculiarities of Adult Learning and Education. Pedagogy. Psychology, Philosophy, 3(03), 30-35 (2016)

14. Y. Tao, Typology of college student perception on institutional e-learning issues - An extension study of a teacher's typology in Taiwan. Computers \& Education, 50(4), 1495-1508 (2008) https://doi.org/10.1016/j.compedu.2007.02.002

15. Y. Wang, Integrating Games, e-Books and AR Techniques to Support Project-based Science Learning. Educational Technology \& Society, 23(3), 53-67 (2020) doi: $10.2307 / 26926426$ 